\title{
CARBONO E NITROGÊNIO DA BIOMASSA MICROBIANA EM RESPOSTA A DIFERENTES SISTEMAS DE MANEJO EM UM LATOSSOLO VERMELHO NO CERRADO ${ }^{(1)}$
}

\author{
Cícero Célio de Figueiredo ${ }^{(2)}$, Dimas Vital Siqueira Resck ${ }^{(3)}$, Antonio Carlos \\ Gomes $^{(3)}$, Eloisa Aparecida Belleza Ferreira ${ }^{(3)}$ \& Maria Lucrecia Gerosa Ramos ${ }^{(4)}$
}

\begin{abstract}
RESUMO
A biomassa microbiana é um componente vivo da matéria orgânica sensível às mudanças causadas pelos diferentes sistemas de manejo do solo. Para alcançar os objetivos propostos neste trabalho, foi realizado um experimento de longa duração na área experimental da Embrapa Cerrados, Planaltina, Distrito Federal. Foram estudados oito sistemas de manejo do solo, formados pelo uso de diferentes implementos agrícolas e épocas de incorporação de restos culturais. As amostras de solo foram coletadas em cinco profundidades: 0-5, 5-10, 10-20, 20-30 e 30-40 cm, com três repetições, em três épocas: antes do plantio do milho, 30 dias após a emergência e na floração da cultura. Os tratamentos sob plantio direto apresentaram diferenças nos teores de $\mathrm{C}$ e $\mathrm{N}$ da biomassa microbiana $\left(\mathrm{C}_{\mathrm{mic}}\right.$ e $\left.\mathrm{N}_{\mathrm{mic}}\right)$ : enquanto um tratamento sob plantio direto, que utilizou arado de aivecas (PDAV) no primeiro ano de cultivo, superou nos teores de $\mathbf{C}_{\text {mic }}$ um outro que utilizou o arado de discos, também no primeiro ano (PDAD), o oposto ocorreu para o conteúdo de $\mathrm{N}_{\text {mic }}$. Isso indica que o efeito desses implementos nas propriedades do solo persistiu mesmo após 22 anos sob plantio direto. Das propriedades do solo analisadas, de maneira geral, as maiores diferenças entre os sistemas sob plantio direto e sob cultivo mínimo (escarificador) e aqueles com maior perturbação do solo (arado de discos e de aivecas) foram verificadas antes do plantio, ou seja, antes do revolvimento e da adubação do solo para estabelecimento da cultura.
\end{abstract}

Termos de indexação: plantio direto, arado de discos, arado de aivecas, escarificador.

\footnotetext{
(1) Parte da Tese de Mestrado do primeiro autor apresentada ao Curso de Ciências Agrárias da Faculdade de Agronomia e Veterinária, Universidade de Brasília - FAV/UnB. Recebido para publicação em agosto de 2003 e aprovado em março de 2007. ${ }^{(2)}$ Doutorando do Programa de Pós-Graduação em Agronomia da Universidade Federal de Goiás - UFGO. Rodovia Goiânia-Nova Veneza, Km 0, Caixa Postal 131, CEP 74001-970 Goiânia (GO). E-mail: cceliofigueiredo@yahoo.com.br

(3) Pesquisadores da Embrapa Cerrados, Caixa Postal 08223, CEP 73310-970 Planaltina (DF). E-mail: dvsresck@cpac.embrapa.br

(4) Professora da FAV/UnB. Caixa Postal 04508, CEP 70910-970 Brasília (DF). E-mail: lucrecia@unb.br
} 


\title{
SUMMARY: MICROBIAL BIOMASS CARBONAND NITROGENINRESPONSE TO DIFFERENT MANAGEMENT SYSTEMS CROPPED WITH CORN IN A RED LATOSOL IN THE CERRADO
}

\begin{abstract}
The microbial biomass is a living component of the organic matter responsive to changes caused by different soil management systems. The objective of this long-term study was to determine microbial biomass carbon and nitrogen in response to different management systems in a clayey Red Latosol cultivated with corn in the Cerrado. The field experiment was conducted on an experimental area of Embrapa Cerrados, Planaltina, in the Federal District. Eight soil management systems with different implements and periods of crop residue incorporation were compared. Soil samples were collected from five layers: $0-5,5-10,10-20,20-30$, and $30-40 \mathrm{~cm}$, with three replicates and in three sampling periods: before corn planting, 30 days after germination and at corn flowering. Treatments under no-till differed from each other regarding the microbial biomass $C_{\text {mic }}$ and $N_{\text {mic }}$ contents: while in one no-till treatment the soil cultivated by moldboard plow in the first year (PDAV) had a higher $C_{\text {mic }}$ content, in the other no-till treatment the soil cultivated by disk plow in the first year $(P D A D)$ had a higher $N_{\text {mic }}$ content. This indicates that the effects in the soil profile caused by disk and moldboard plowing are still measurable, even after 22 years under no-till. In general, the greatest differences between no-till (PDAD and PDAV) or minimum tillage (chisel plow), and those with greater soil disturbance (disk and moldboard plow) were observed before planting, that is, before soil plowing and fertilization for the crop.
\end{abstract}

Index terms: no-till, disk plow, moldboard plow, chisel.

\section{INTRODUÇÃO}

O preparo do solo antes do plantio visa melhorar suas condições estruturais, para facilitar a aeração, a penetração de raízes e o fornecimento de nutrientes e água para o crescimento e desenvolvimento das plantas. Entretanto, a modernização das práticas agrícolas levou, nas últimas décadas, ao uso indiscriminado de diversos implementos de preparo do solo, especialmente a grade pesada. Os solos do Cerrado, devido ao uso inadequado desse implemento, têm apresentado efeitos negativos, principalmente relacionados à diminuição dos teores de MOS, sendo comum encontrar relação entre a maior intensidade de revolvimento e os menores teores de MOS nesses solos (Resck \& Silva, 1995; Silva \& Resck, 1997; Corazza et al., 1999).

A biomassa microbiana do solo (BMS) é definida como a parte viva da MOS, composta por todos os microrganismos menores que $5 \times 10^{-3} \mu \mathrm{m}$, como fungos, bactérias e actinomicetos, e pela microfauna, como os protozoários. A BMS é um componente lábil da fração orgânica do solo e representa de 1 a $4 \%$ do $\mathrm{C}$ orgânico total do solo (Corg) e mais de $5 \%$ do N total do solo (Jenkinson \& Polwlson, 1976). As determinações de $\mathrm{C}$ e $\mathrm{N}$ da BMS $\left(\mathrm{C}_{\text {mic }}\right.$ e $\left.\mathrm{N}_{\text {mic }}\right)$ demonstram ser propriedades sensíveis para quantificar as mudanças no manejo do solo (Carter \& Rennie, 1982). Em geral, a quantidade da BMS é regulada pela disponibilidade de nutrientes, pela capacidade de proteção do solo (estrutura e estabilidade dos agregados), além da temperatura e da umidade (Bonde et al., 1988).

Poucos trabalhos têm estudado a BMS em solos do Cerrado submetidos a diferentes sistemas de manejo.
Destes, a maior parte utiliza exclusivamente a quantificação do $\mathrm{C}_{\text {mic }}$ (Saminêz, 1999; Oliveira, 2000). Entretanto, a determinação simultânea de $\mathrm{N}_{\text {mic }}$ e $\mathrm{C}_{\text {mic }}$ possibilita conhecer, além das relações $\mathrm{C}_{\text {mic }}: \mathrm{C}_{\text {org }} \mathrm{e}$ $\mathrm{N}_{\text {mic }}: \mathrm{N}_{\text {total }}$, que indicam qualidade da MOS (Wardle, 1992), a estrutura e o estado da comunidade microbiana (Anderson \& Domsch, 1980; Campbell et al., 1991; Moore et al., 2000). Além disso, de acordo com Wardle (1992), na maior parte dos estudos, a proporção de $\mathrm{C}$ de compostos orgânicos imobilizados na BMS foi mais positivamente relacionada com o $\mathrm{N}$ do que com o $\mathrm{C}$ oriundo de substratos. Isso significa que, em muitos sistemas, o $\mathrm{N}$, mais do que o $\mathrm{C}$, influenciou a imobilização de $\mathrm{C}$ orgânico (Corg) na BMS.

É necessário, portanto, entender o efeito de diferentes sistemas de manejo do solo sobre a quantidade da BMS e sua ação na liberação e no fornecimento adequados de nutrientes para as culturas no Cerrado.

Este trabalho teve como principal objetivo avaliar os teores de $\mathrm{C} \mathrm{e} \mathrm{N}$ da biomassa microbiana em resposta a diferentes sistemas de manejo, em um Latossolo Vermelho cultivado com milho no Cerrado.

\section{MATERIAL E MÉTODOS}

\section{Localização e características da área experi- mental}

O trabalho foi desenvolvido no campo experimental da Embrapa Cerrados, localizado em Planaltina, DF 
$\left(15^{\circ} 35^{\prime} 30^{\prime}\right.$ ' S e $47^{\circ} 42^{\prime} 00$ ” W). O clima da região corresponde ao tipo Aw (tropical chuvoso), segundo classificação de Köppen, com presença de invernos secos e verões chuvosos. Uma característica marcante do clima local, e do Cerrado de maneira geral, é um período sem chuvas dentro da estação chuvosa, conhecido como veranico (Adámoli et al., 1986).

Os tratamentos foram instalados em um Latossolo Vermelho argiloso (Quadro 1).

\section{Sistemas de manejo estudados}

A área experimental corresponde a um experimento de longa duração, instalado no ano de 1979, constituído de oito parcelas de $1.250 \mathrm{~m}^{2}$, com os seguintes tratamentos: (1) ADPP: preparo com arado de discos préplantio (em que o solo é revolvido a uma profundidade de aproximadamente $25 \mathrm{~cm}$ com arado de discos apenas uma vez ao ano: no início do período chuvoso, na época do plantio, em outubro/novembro); (2) ADPC: preparo com arado de discos pós-colheita (nesse sistema, o solo é revolvido com arado de discos e os resíduos são incorporados a uma profundidade de aproximadamente $25 \mathrm{~cm}$ duas vezes ao ano: logo após a colheita da cultura, no mês de maio, no final da estação chuvosa, e antes do plantio, nos meses de outubro/ novembro, no início da estação chuvosa); (3) AVPP: preparo com arado de aivecas pré-plantio (o solo é revolvido com arado de aivecas a uma profundidade de aproximadamente $40 \mathrm{~cm}$ apenas uma vez ao ano: na época do plantio da cultura, em outubro/novembro); (4) AVPC: preparo com arado de aivecas pós-colheita (nesse sistema, o solo é revolvido com arado de aivecas a uma profundidade de aproximadamente $40 \mathrm{~cm}$ duas vezes ao ano: logo após a colheita da cultura, no mês de maio, no final da estação chuvosa, e antes do plantio, nos meses de outubro/novembro, no início da estação chuvosa); (5) ESCAD: preparo com escarificador, antes do plantio, a partir do segundo ano em área preparada com arado de discos em 1979, primeiro ano de cultivo; (6) ESCAV: preparo com escarificador, antes do plantio, a partir do segundo ano em área preparada com arado de aivecas em 1979, primeiro ano de cultivo; (7) PDAD: plantio direto a partir do segundo ano em área preparada com arado de discos em 1979, primeiro ano de cultivo; e (8) PDAV: plantio direto a partir do segundo ano em área preparada com arado de aivecas em 1979, primeiro ano de cultivo. Durante os 22 anos, todos os tratamentos foram cultivados com as mesmas culturas, representadas principalmente pelo cultivo alternado de milho e soja. Os implementos utilizados em cada tratamento foram os mesmos durante os 22 anos.

\section{Épocas e profundidades de amostragem do solo}

Em cada parcela foi traçada uma diagonal, em que foram alocados três pontos de amostragem, eqüidistantes de $21 \mathrm{~m}$, com os pontos extremos a $6 \mathrm{~m}$ da borda limítrofe da parcela, que se constituíram nas repetições de cada tratamento. Cada amostra foi composta por cinco subamostras, coletadas eqüidistantes ao redor desses pontos. As coletas de amostras de solo foram realizadas em outubro e dezembro de 2001 (antes do plantio do milho e 30 dias após a emergência - DAE, respectivamente) e em fevereiro de 2002 (floração), em cinco profundidades: $0-5,5-10,10-20,20-30$ e $30-40 \mathrm{~cm}$.

Quadro 1. Características químicas e físicas do solo estudado(1). Os valores correspondem às médias e desvios-padrão de amostras de cada profundidade $(n=24)$

\begin{tabular}{|c|c|c|c|c|c|}
\hline \multirow{2}{*}{ Característica } & \multicolumn{5}{|c|}{ Profundidade $(\mathrm{cm})$} \\
\hline & $0-5$ & $5-10$ & $10-20$ & $20-30$ & $30-40$ \\
\hline Corg $\left(\mathrm{g} \mathrm{kg}^{-1}\right)$ & $19 \pm 0,3$ & $18 \pm 0,2$ & $16 \pm 0,2$ & $15 \pm 0,2$ & $12 \pm 0,2$ \\
\hline $\mathrm{pH}\left(\mathrm{H}_{2} \mathrm{O}\right)$ & $5,4 \pm 0,2$ & $5,4 \pm 0,2$ & $5,3 \pm 0,2$ & $5,3 \pm 0,3$ & $5,1 \pm 0,3$ \\
\hline $\mathrm{Al}^{3+}\left(\mathrm{cmol}_{\mathrm{c}} \mathrm{kg}^{-1}\right)$ & $0,1 \pm 0,1$ & $0,1 \pm 0,1$ & $0,3 \pm 0,3$ & $0,3 \pm 0,3$ & $0,6 \pm 0,3$ \\
\hline $\mathrm{Ca}^{2+}\left(\mathrm{cmol}_{\mathrm{c}} \mathrm{kg}^{-1}\right)$ & $3,6 \pm 0,8$ & $3,6 \pm 0,7$ & $3,1 \pm 1,0$ & $2,5 \pm 0,6$ & $1,5 \pm 0,5$ \\
\hline $\mathrm{Mg}^{2+}\left(\mathrm{cmol}_{\mathrm{c}} \mathrm{kg}^{-1}\right)$ & $1,4 \pm 0,6$ & $1,2 \pm 0,5$ & $1,0 \pm 0,5$ & $0,8 \pm 0,2$ & $0,4 \pm 0,1$ \\
\hline $\mathrm{P}\left(\mathrm{mg} \mathrm{kg}^{-1}\right)$ & $9,2 \pm 1,9$ & $11,8 \pm 5,3$ & $8,1 \pm 2,8$ & $3,3 \pm 1,3$ & $1,3 \pm 1,2$ \\
\hline $\mathrm{K}\left(\mathrm{mg} \mathrm{kg}^{-1}\right)$ & $211 \pm 71,7$ & $113,1 \pm 18,9$ & $50,8 \pm 22,9$ & $34,1 \pm 12,4$ & $22,7 \pm 9,7$ \\
\hline $\mathrm{H}+\mathrm{Al}\left(\mathrm{cmol}_{\mathrm{c} \mathrm{kg}}{ }^{-1}\right)$ & $5,6 \pm 1,0$ & $5,9 \pm 1,0$ & $6,1 \pm 1,3$ & $6,2 \pm 1,1$ & $6,2 \pm 0,9$ \\
\hline Dens.Solo $\left(\mathrm{kg} \mathrm{dm}^{-3}\right)$ & $1,1 \pm 0,09$ & $1,0 \pm 0,07$ & $1,0 \pm 0,06$ & $1,0 \pm 0,04$ & $1,0 \pm 0,00$ \\
\hline Argila (\%) & $41,1 \pm 2,47$ & $41,3 \pm 1,83$ & $42,3 \pm 1,67$ & $42,1 \pm 2,03$ & $43,0 \pm 2,27$ \\
\hline Silte $(\%)$ & $9,9 \pm 1,25$ & $9,4 \pm 0,52$ & $9,1 \pm 0,83$ & $9,5 \pm 1,31$ & $9,5 \pm 1,31$ \\
\hline Areia (\%) & $49,1 \pm 1,96$ & $49,8 \pm 2,05$ & $48,9 \pm 1,25$ & $48,5 \pm 1,51$ & $47,5 \pm 1,77$ \\
\hline
\end{tabular}

(1) Analisado seguindo os métodos da Embrapa (1997). 
O milho, cultivar BR 205, foi plantado em 16 de novembro de 2001. A adubação de plantio, comum a todos os tratamentos, foi de $500 \mathrm{~kg} \mathrm{ha}^{-1}$ da fórmula 0-20-20 mais $48 \mathrm{~kg} \mathrm{ha}^{-1}$ de FTE BR 12. A adubação nitrogenada, com sulfato de amônio (90 $\left.\mathrm{kg} \mathrm{ha}^{-1} \mathrm{de} \mathrm{N}\right)$, foi parcelada em três épocas ( $30 \mathrm{~kg} \mathrm{ha}^{-1}$ de $\mathrm{N}$ por vez): no plantio e aos 20 e 45 dias após o plantio (DAP), quando as plantas apresentavam de 4 a 6 e 8 a 10 folhas, respectivamente. A colheita foi realizada em 19 de abril de 2002.

\section{Avaliação da biomassa microbiana (BMS) do solo}

A BMS foi estimada utilizando-se o método de fumigação-extração (Brookes et al., 1985; Vance et al., 1987). $\mathrm{O} \mathrm{C}_{\text {mic }}$ e o $\mathrm{N}_{\text {mic }}$ foram determinados na mesma amostra de solo obedecendo uma relação solo:extrator de 1:2,5 (De-Polli \& Guerra, 1999). As amostras, após a coleta, foram imediatamente levadas para uma câmara fria, permanecendo armazenadas, sob temperatura de aproximadamente $4{ }^{\circ} \mathrm{C}$, até as análises. Os resíduos da cultura, como raízes e restos vegetais, foram removidos cuidadosamente das amostras de solo, antes de estas serem passadas em peneira de $8 \mathrm{~mm}$ de malha. Foram pesadas seis subamostras de $20 \mathrm{~g}$ de solo para cada amostra de campo (em triplicata), com teor de água ajustado para estar em equilíbrio com uma tensão de $30 \mathrm{kPa}(\sim 80 \%$ da capacidade de campo do solo). Essas amostras foram pré-incubadas à temperatura ambiente $\left(26 \pm 2{ }^{\circ} \mathrm{C}\right)$, por sete dias, em recipientes fechados de $600 \mathrm{~mL}$, no escuro. Após esse período, três subamostras foram fumigadas (F) em um dessecador contendo uma placa de Petri com $25 \mathrm{~mL}$ de clorofórmio isento de etanol $\left(\mathrm{CHCl}_{3}\right)$, por $24 \mathrm{~h}$. As outras três subamostras não-fumigadas (NF) foram mantidas em temperatura ambiente. Após a fumigação, as subamostras $\mathrm{F}$ e NF foram submetidas à agitação horizontal $(150 \mathrm{rpm})$ por $30 \mathrm{~min}$, na presença de $50 \mathrm{~mL}$ de solução extratora $\left(\mathrm{K}_{2} \mathrm{SO}_{4} 0,5 \mathrm{~mol} \mathrm{~L}^{-1}\right)$. Em seguida, as subamostras foram filtradas em papel-filtro qualitativo.

\section{Carbono da biomassa microbiana}

$\mathrm{O}$ carbono da biomassa microbiana $\left(\mathrm{C}_{\text {mic }}\right)$ foi determinado de acordo com Vance et al. (1987). Uma alíquota de $8 \mathrm{~mL}$ do extrato filtrado foi utilizada para essa determinação. A esta alíquota foram acrescentados $2 \mathrm{~mL}$ de $\mathrm{K}_{2} \mathrm{Cr}_{2} \mathrm{O}_{7} 0,4 \mathrm{~mol} \mathrm{~L}^{-1}$ e $15 \mathrm{~mL}$ de uma mistura 1:2 (v/v) de $\mathrm{H}_{2} \mathrm{SO}_{4} / \mathrm{H}_{3} \mathrm{PO}_{4}$ em erlenmeyers de $250 \mathrm{~mL}$. Esta solução foi fervida sob refluxo por $30 \mathrm{~min}$, resfriada e diluída com $20 \mathrm{~mL}$ de água destilada adicionados pelo condensador. O dicromato residual foi quantificado por titulação com uma solução de sulfato ferroso amoniacal $\left[\left(\mathrm{NH}_{4}\right)_{2} \mathrm{Fe}\left(\mathrm{SO}_{4}\right)_{2} \cdot 6 \mathrm{H}_{2} \mathrm{O}\right]$ em $\mathrm{H}_{2} \mathrm{SO}_{4}$ concentrado, na presença de um indicador composto por fenantrolina $0,075 \mathrm{~mol} \mathrm{~L}^{-1} \mathrm{e}$ sulfato ferroso $0,041 \mathrm{~mol} \mathrm{~L}^{-1}$.

A quantidade de $\mathrm{C}_{\text {mic }}$ foi determinada pela diferença entre o C extraído das amostras de solo $\mathrm{F}$ e NF, usandose fator de correção $\left(\mathrm{k}_{\mathrm{C}}\right)$ de 0,35 (Joergensen, 1995).

\section{Nitrogênio da biomassa microbiana}

$\mathrm{O}$ nitrogênio da biomassa microbiana $\left(\mathrm{N}_{\text {mic }}\right)$ foi determinado de acordo com Brookes et al. (1985). Outra alíquota de $20 \mathrm{~mL}$ do extrato filtrado foi utilizada para essa determinação. $\mathrm{O} N$ total dos extratos F e NF foi determinado empregando-se o método Kjeldahl, da seguinte forma: a alíquota foi transferida para um tubo de vidro na presença de $3 \mathrm{~mL}$ de $\mathrm{H}_{2} \mathrm{SO}_{4}$ concentrado e de $1 \mathrm{~g}$ de mistura catalítica $\left(\mathrm{K}_{2} \mathrm{SO}_{4}: \mathrm{CuSO}_{4}\right.$ : Se em pó, na relação 1: 0,1: 0,01). Em seguida, os tubos foram acondicionados em bloco digestor. Realizou-se uma pré-digestão a $80^{\circ} \mathrm{C}$ por uma noite. Em seguida, a temperatura foi mantida a $150{ }^{\circ} \mathrm{C}$ durante uma hora e meia, sendo a digestão concluída a $300{ }^{\circ} \mathrm{C}$, durante três horas. Iniciou-se, em seguida, a destilação com adição de $20 \mathrm{~mL}$ de $\mathrm{NaOH} 400 \mathrm{~g} \mathrm{~L}^{-1}$, recolhendo-se o destilado em erlenmeyer de $50 \mathrm{~mL}$ contendo $10 \mathrm{~mL}$ de $\mathrm{H}_{3} \mathrm{BO}_{3}$ $\left(20 \mathrm{~g} \mathrm{~L}^{-1}\right)$, na presença de um indicador composto por verde de bromocresol $\left(0,1 \mathrm{dag} \mathrm{L}^{-1}\right)$ e vermelho de metila $\left(0,1\right.$ dag $\left.\mathrm{L}^{-1}\right)$, procedendo-se então à titulação com $\mathrm{H}_{2} \mathrm{SO}_{4} 0,0025 \mathrm{~mol} \mathrm{~L}^{-1}$. O N $\mathrm{Nic}_{\text {mic }}$ foi calculado pela diferença entre a quantidade de $\mathrm{N}$ recuperado no extrato da amostra $\mathrm{F}$ e a verificada na amostra NF, multiplicada pelo fator de correção $\mathrm{k}_{\mathrm{N}}$ igual a 0,54 , preconizado por Brookes et al. (1985).

\section{Análises estatísticas}

Utilizou-se o programa denominado "Profile" (Colwell, 1978) para diferenciação estatística dos tratamentos, por meio da análise de variância dos valores dos parâmetros de uma regressão polinomial ortogonal, em que y representa as propriedades do solo $\left(\mathrm{C}_{\text {mic }}\right.$ e $\left.\mathrm{N}_{\text {mic }}\right)$ e o x são os valores nas profundidades consideradas neste estudo. Os parâmetros $\mathrm{p}_{0}, \mathrm{p}_{1}, \mathrm{p}_{2} \mathrm{e}$ $\mathrm{p}_{3}$, independentes entre si, foram estimados para cada repetição amostral, considerando-se os pontos médios nos intervalos de profundidade amostrados $-2,5 \mathrm{~cm}$ $(0-5 \mathrm{~cm}), 7,5 \mathrm{~cm}(5-10 \mathrm{~cm}), 15 \mathrm{~cm}(10-20 \mathrm{~cm}), 25 \mathrm{~cm}$ $(20-30 \mathrm{~cm})$ e $35 \mathrm{~cm}(30-40 \mathrm{~cm})$ - e comparando esses parâmetros com o teste t a $5 \%$. Foi utilizado o modelo de regressão polinomial ortogonal $y=p_{0}+p_{1} x_{L}+p_{2} x_{Q}$ $+\mathrm{p}_{3} \mathrm{x}_{\mathrm{C}}$ (Quadro 2), em que $\mathrm{p}_{0}$ representa o efeito médio dos tratamentos no perfil e os parâmetros da regressão $\mathrm{p}_{1}, \mathrm{p}_{2}$ e $\mathrm{p}_{3}$ representam a quantidade e a direção (sinal) de cada tendência linear, quadrática e cúbica dos teores de $\mathrm{C}_{\text {mic }}$ e de $\mathrm{N}_{\text {mic }}$ em profundidade $(\mathrm{cm})$, respectivamente. Os valores de $\mathrm{X}_{\mathrm{L}}, \mathrm{X}_{\mathrm{Q}}$ e $\mathrm{X}_{\mathrm{C}}$ referemse ao coeficiente linear, quadrático e cúbico, respectivamente, dos polinômios ortogonais para a interpolação, obtidos por meio de um programa escrito em linguagem Fortran (Quadro 3) (Colwell, 1978).

Utilizou-se também a regressão não-ortogonal $\hat{y}=b_{0}+b_{1} x+b_{2} x^{2}+b_{3} x^{3}$, em que $b_{0}, b_{1}, b_{2}$ e $b_{3}$ são interdependentes e representam os estimadores dos parâmetros para o intercepto e os efeitos linear, quadrático e cúbico, respectivamente, para cálculos estimativos dos valores finais da variável $\mathrm{N}_{\text {mic }}$ e da 
Quadro 2. Parâmetros e coeficientes de uma equação de regressão polinomial ortogonal

Descrição do comportamento
Parâmetro e coeficiente da equação que formam o polinômio

\begin{tabular}{ll} 
Tendência zero (efeito médio dos tratamentos) & $\hat{y}=p_{0}$ \\
Tendência linear & $\hat{y}=p_{1} x_{L}$ \\
Tendência quadrática & $\hat{y}=p_{2} x_{Q}$ \\
Tendência cúbica & $\hat{y}=p_{3} x_{C}$ \\
Equação completa & $\hat{y}=p_{0}+p_{1} x_{L}+p_{2} x_{Q}+p_{3} x_{C}$ \\
\hline
\end{tabular}

Quadro 3. Coeficientes para interpolação de polinômios ortogonais para os diferentes sistemas de manejo

\begin{tabular}{ccc}
\hline \multirow{2}{*}{ Profundidade $(\mathbf{c m})$} & \multicolumn{2}{c}{ Coeficiente de interpolação } \\
\cline { 2 - 3 } & $\mathbf{X}_{\mathbf{L}}$ (linear) & $\mathbf{X}_{\mathbf{Q}}$ (quadrático) \\
\hline 2,5 & $-5,8$ & 19,62093 \\
7,5 & $-3,8$ & $-2,38629$ \\
15 & $-0,8$ & $-20,3971$ \\
25 & 3,2 & $-16,4115$ \\
35 & 7,2 & 19,57402 \\
\hline
\end{tabular}

relação $\mathrm{C}_{\text {mic }}: \mathrm{N}_{\text {mic }}$, em relação à profundidade $\mathrm{x}(\mathrm{cm})$. Neste trabalho foram apresentados e discutidos somente os interceptos, $\mathrm{p}_{0}$ e $\mathrm{b}_{0}$, e as estimativas dos parâmetros $\mathrm{p}_{1}$ e $\mathrm{b}_{1}$, com os respectivos valores de $\mathrm{R}^{2}$ calculados para as equações de regressão polinomial completas.

\section{RESULTADOS E DISCUSSÃO}

Carbono da biomassa microbiana em três épocas e cinco profundidades durante o ciclo do milho

Os valores obtidos para $\mathrm{C}_{\text {mic }}$ nos diferentes tratamentos (Quadro 4) foram semelhantes aos já encontrados anteriormente por outros autores, sob condições edafoclimáticas diversas (Alvarez et al., 1995; Balota et al., 1998). Considerando o efeito médio da variável $\mathrm{C}_{\mathrm{mic}}$ no perfil do solo $\left(\mathrm{p}_{0}\right)$, verificou-se que no tratamento PDAV ( $\mathrm{p}_{0}=261 \mathrm{mg} \mathrm{kg}^{-1} \mathrm{de} \mathrm{C}$ no solo), antes do plantio, o valor de $\mathrm{C}_{\text {mic }}$ foi significativamente superior ao dos demais tratamentos, com exceção do

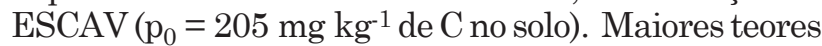
de $\mathrm{C}_{\text {mic }}$ no sistema plantio direto, quando comparado com preparo com aração, são comuns em estudos com solos das diferentes regiões do mundo (Alvarez et al., 1997; Balota et al., 1998; Guggenberger et al., 1999).
Aos 30 DAE, o tratamento ESCAD apresentou os maiores valores ( $\left.\mathrm{p}_{0}=339 \mathrm{mg} \mathrm{kg}^{-1} \mathrm{de} C\right)$ e só não diferiu do PDAV ( $\mathrm{p}_{0}=219 \mathrm{mg} \mathrm{kg}^{-1} \mathrm{de} \mathrm{C}$ ), sendo significativamente superior a todos os demais tratamentos, que não diferiram entre si. Esses resultados sugerem que o uso do escarificador (com revolvimento mínimo do solo) também favorece a produção de biomassa microbiana, por apresentar condições de solo semelhantes às do plantio direto. As diferenças encontradas entre os dois sistemas sob plantio direto, na época antes do plantio, e entre os sistemas com escarificação, aos $30 \mathrm{DAE}$, demonstram que as alterações diferenciadas promovidas pelos arados de discos e aivecas, no primeiro ano do experimento, permanecem nesses sistemas mesmo após 22 anos sem o uso desses implementos. Observa-se, no entanto, que aos 30 DAE, no escarificador, o arado de discos proporcionou condições para o aumento da biomassa microbiana em relação ao arado de aivecas $(\mathrm{ESCAD}=$ $339>$ ESCAV $=171)$. No PD, antes do plantio, o arado de discos deu condições para a diminuição da biomassa microbiana, comparado ao arado de aivecas $(\mathrm{PDAD}=197<\mathrm{PDAV}=261)$.

Na floração, no entanto, o modelo polinomial não foi significativo para esses tratamentos.

A variação da biomassa microbiana no perfil é dada pelo estimador do parâmetro $\mathrm{p}_{1}$, que representa a taxa 
de redução linear com a profundidade $\left(\mathrm{mg} \mathrm{kg}^{-1} \mathrm{de} \mathrm{C}\right.$ no solo por $\mathrm{cm}$ de profundidade). Nesse caso, a maior taxa de redução linear de $\mathrm{C}$ ocorreu no tratamento PDAV $\left(\mathrm{p}_{1}=-25,7 \mathrm{mg} \mathrm{kg}^{-1}\right)$ (Quadro 5), não diferindo apenas do PDAD $\left(\mathrm{p}_{1}=-20,6 \mathrm{mg} \mathrm{kg}^{-1} \mathrm{~cm}^{-1}\right)$. Os demais tratamentos que tiveram algum tipo de revolvimento não diferiram entre si. Para se conhecer o valor da biomassa microbiana, no tratamento PDAV, antes do plantio, por exemplo, a $15 \mathrm{~cm}$ de profundidade no perfil, seria necessário multiplicar o estimador $\mathrm{p}_{1}=-25,7$
(Quadro 5) pelo coeficiente de interpolação linear $\mathrm{X}_{\mathrm{L}}=$ $-0,8$ (Quadro 3) e somar o resultado a $\mathrm{p}_{0}=261 \mathrm{mg} \mathrm{kg}^{-1}$ de $\mathrm{C}$ no solo (Quadro 4), ficando a equação $\mathrm{C}_{\text {mic }}$ $(\mathrm{PDAV})=261-25,7 \mathrm{X}_{\mathrm{L}}$, ou C $_{\mathrm{mic}}=281,56 \mathrm{mg} \mathrm{kg}^{-1} \mathrm{de} \mathrm{C}$ no solo na profundidade de $15 \mathrm{~cm}$. Semelhantemente à estratificação e diminuição da $\mathrm{MO}$ com o aumento da profundidade, há decréscimo acentuado dos valores de $\mathrm{C}_{\text {mic }}$ nos sistemas sob plantio direto, expresso pelo valor negativo de $\mathrm{p}_{1}$ (Resck et al., 1995; Resck, 1997; Corazza et al., 1999).

Quadro 4. Comparação dos estimadores do parâmetro $p_{0}$ da regressão $\hat{y}=p_{0}+p_{1} x_{L}$ para carbono da biomassa microbiana $\left(C_{\text {mic }}\right)$ em oito tratamentos e em três épocas de amostragem

\begin{tabular}{|c|c|c|c|}
\hline \multirow{2}{*}{ Tratamento } & \multicolumn{3}{|c|}{ Intercepto po para as épocas } \\
\hline & Antes do plantio (**) & 30 DAE (*) & Floração \\
\hline & & & \\
\hline $\operatorname{ADPP}^{(1)}$ & $156 \mathrm{bc}^{(2)}$ & $155 \mathrm{~b}$ & 206 a \\
\hline $\mathrm{ADPC}$ & $131 \mathrm{c}$ & $128 \mathrm{~b}$ & $160 \mathrm{a}$ \\
\hline ESCAD & $200 \mathrm{~b}$ & 339 a & $171 \mathrm{a}$ \\
\hline PDAD & $19 \mathrm{~b}$ & $113 \mathrm{~b}$ & $137 \mathrm{a}$ \\
\hline AVPP & $157 \mathrm{bc}$ & $148 \mathrm{~b}$ & $127 \mathrm{a}$ \\
\hline AVPC & $191 \mathrm{~b}$ & $159 \mathrm{~b}$ & 219 a \\
\hline ESCAV & $205 \mathrm{ab}$ & $171 \mathrm{~b}$ & $170 \mathrm{a}$ \\
\hline PDAV & $261 \mathrm{a}$ & $219 \mathrm{ab}$ & 202 a \\
\hline
\end{tabular}

(1) ADPP: preparo com arado de discos pré-plantio; ADPC: arado de discos pós-colheita; AVPP: arado de aivecas pré-plantio; AVPC: arado de aivecas pós-colheita; ESCAD: escarificador a partir do segundo ano em área preparada com arado de discos em 1979, primeiro ano de cultivo; ESCAV: escarificador a partir do segundo ano em área preparada com arado de aivecas em 1979, primeiro ano de cultivo; PDAD: plantio direto a partir do segundo ano em área preparada com arado de discos em 1979, primeiro ano de cultivo; PDAV: plantio direto a partir do segundo ano em área preparada com arado de aivecas em 1979, primeiro ano de cultivo. ${ }^{(2)}$ Valores seguidos da mesma letra na coluna não apresentam diferenças significativas entre si pelo teste $\mathrm{t}$ a $5 \%$. *, **: Significativos a 5 e $1 \%$, respectivamente; ns: não-significativo, pelo teste F. DAE = dias após emergência.

Quadro 5. Comparação dos estimadores do parâmetro $p_{1}$ da regressão $\hat{y}=p_{0}+p_{1} x_{L}$ para carbono da biomassa microbiana $\left(C_{\text {mic }}\right)$ em oito tratamentos e em três épocas de amostragem

\begin{tabular}{|c|c|c|c|}
\hline \multirow{2}{*}{ Tratamento } & \multicolumn{3}{|c|}{ Parâmetro p para as épocas } \\
\hline & Antes do plantio (*) & 30 DAE (*) & Floração (ns) \\
\hline & \multicolumn{3}{|c|}{$\mathrm{mg} \mathrm{kg}^{-1}$ de $\mathrm{C}$ por $\mathrm{cm}$ de profundidade } \\
\hline $\operatorname{ADPP}^{(1)}$ & $-12,1 \mathrm{ab}^{(2)}$ & $-4,96 a b$ & $-8,74 \mathrm{a}$ \\
\hline ADPC & $-6,48 \mathrm{a}$ & $-12,0 \mathrm{ab}$ & $-11,9$ a \\
\hline ESCAD & $-13,5 \mathrm{ab}$ & $-20,5 \mathrm{~b}$ & $-10,8 \mathrm{a}$ \\
\hline PDAD & $-20,6 \mathrm{bc}$ & $-13,0 \mathrm{~b}$ & $-21,6$ a \\
\hline AVPP & $-11,3 \mathrm{ab}$ & $4,49 \mathrm{a}$ & $-2,00 \mathrm{a}$ \\
\hline AVPC & $-10,1 \mathrm{a}$ & $-4,23 a b$ & $-21,1 \mathrm{a}$ \\
\hline ESCAV & $-15,3 \mathrm{ab}$ & $-15,0 \mathrm{~b}$ & $-9,33 \mathrm{a}$ \\
\hline PDAV & $-25,7 \mathrm{c}$ & $-14,9 \mathrm{~b}$ & $-6,84 \mathrm{a}$ \\
\hline
\end{tabular}

\footnotetext{
(1) Idem à descrição apresentada no quadro 4. ${ }^{(2)}$ Valores seguidos da mesma letra na coluna não apresentam diferenças significativas entre si pelo teste t a $5 \%$.
}

*: Significativo a $5 \%$; ns: não-significativo pelo teste F. 
Maior teor de $\mathrm{C}_{\text {mic }}$ nas camadas superficiais do solo, com maior redução nas camadas mais profundas de solos sob plantio direto, tem sido verificado por vários autores em solos de diversas regiões do mundo (Lynch \& Panting, 1980; Alvarez et al., 1997; Salinas-Garcia et al., 1997; Balota et al., 1998).

No presente estudo, aos 30 DAE somente houve diferença significativa para o tratamento AVPP (4,49 $\mathrm{mg} \mathrm{kg}^{-1}$ de $\mathrm{C}$ no solo por $\mathrm{cm}$ de profundidade), com valor menor que nos tratamentos PDAD, PDAV, $\operatorname{ESCAD}$ e $\operatorname{ESCAV}\left(\mathrm{p}_{1}=-13,0,-14,9,-20,5\right.$ e $-15,0 \mathrm{mg} \mathrm{kg}^{-1}$ de $\mathrm{C}$ de solo por $\mathrm{cm}$ de profundidade, respectivamente). Não houve diferenças significativas entre os tratamentos AVPC, ADPP e ADPC.

\section{Nitrogênio da biomassa microbiana}

Considerando-se o efeito médio da variável $\mathrm{N}_{\text {mic }}$ no perfil do solo $\left(\mathrm{p}_{0}\right)$, na época antes do plantio, o maior valor de $\mathrm{N}_{\text {mic }}\left(\mathrm{p}_{0}=28,1 \mathrm{mg} \mathrm{kg}^{-1}\right.$ de $\mathrm{N}$ no solo) foi encontrado no sistema PDAD (Quadro 6), não diferindo apenas dos tratamentos PDAV e ESCAV $\left(\mathrm{p}_{0}=22,9 \mathrm{e}\right.$ $20,4 \mathrm{mg} \mathrm{kg}^{-1}$ de $\mathrm{N}$, respectivamente), tendo sido 2,4 vezes maior que o do $\operatorname{AVPC}\left(\mathrm{p}_{0}=11,7 \mathrm{mg} \mathrm{kg}^{-1} \mathrm{de} \mathrm{N}\right)$.

Já aos 30 DAE nota-se maior equilíbrio entre os valores do efeito médio no perfil $\left(\mathrm{p}_{0}\right)$ para $\mathrm{N}_{\text {mic }}$. Entretanto, observa-se que o $\operatorname{ADPP}\left(\mathrm{p}_{0}=26,2 \mathrm{mg} \mathrm{kg}^{-1}\right.$ de $\mathrm{N}$ de solo) apresentou valor superior ao dos demais tratamentos que utilizaram arado de aivecas e de discos e um plantio direto (AVPP, AVPC, ADPC e PDAV; 16,8, 15,7, 13,3 e 17,8 $\mathrm{mg} \mathrm{kg}^{-1}$ de $\mathrm{N}$, respectivamente), sendo quase duas vezes maior que o ADPC e 1,5 vez em relação ao PDAV ( $\mathrm{p}_{0}=$ $17,8 \mathrm{mg} \mathrm{kg}^{-1}$ de N). Uma explicação para esse fato é que no sistema ADPP os restos culturais da cultura do ano agrícola anterior ficam sobre a superfície. Com o início das chuvas, é feito o preparo do solo e a incorporação desses restos culturais, o que, juntamente com a adubação nitrogenada no plantio e a primeira cobertura, aumentaria o $\mathrm{N}$ na biomassa. Esse fato já foi verificado por outros autores. Por exemplo, Francis et al. (1992) constataram que a mineralização de compostos nitrogenados ocorre de maneira mais constante sob plantio direto, enquanto, sob cultivo convencional, há elevada liberação de N logo após o preparo do solo, devido à quebra dos seus agregados, que causa a intensificação da atividade microbiana. Isso faz com que o sistema de manejo ADPP tenha valor de $\mathrm{N}_{\text {mic }}$ semelhante ao dos sistemas conservacionistas (PDAD, PDAV, ESCAD e ESCAV), com exceção de PDAV. Na floração, no entanto, a diferença entre $\mathrm{p}_{0}$ dos modelos não foi significativa para esses tratamentos.

Os valores de $\mathrm{N}_{\text {mic }}$ variaram de $11,7 \mathrm{mg} \mathrm{kg}^{-1}$ de $\mathrm{N}$ no AVPC, antes do plantio, a $28,1 \mathrm{mg} \mathrm{kg}^{-1}$ de $\mathrm{N}$ no PDAD, também antes do plantio. Considerando que esses valores representam o efeito médio do perfil $\left(\mathrm{p}_{0}\right)$, eles estão de acordo com resultados encontrados por Maciel et al. (1996) em trabalho com solos hidromórficos cultivados com milho e com adubação orgânica, cujos valores de $\mathrm{N}$ variaram de $18 \pm 5$ a $59 \pm$ $10 \mathrm{mg} \mathrm{kg}^{-1}$ de $\mathrm{N}$, considerando-se apenas a camada de 0 a $20 \mathrm{~cm}$. Esses autores encontraram também, em Latossolo Vermelho-Escuro ainda sob vegetação de Cerrado, valores de $\mathrm{N}_{\text {mic }}$ variando de $30 \pm 6 \mathrm{mg} \mathrm{kg}^{-1}$ de $\mathrm{N}$ a $44 \pm 5 \mathrm{mg} \mathrm{kg}^{-1}$ de $\mathrm{N}$, também na camada de 0 a $20 \mathrm{~cm}$. Valores próximos também foram encontrados por Vargas \& Scholles (1998), cujos conteúdos de $\mathrm{N}_{\text {mic }}$, em diferentes sistemas de culturas e épocas de amostragem, até a profundidade de 0 a $15 \mathrm{~cm}$, variaram de 21 a $59 \mathrm{mg} \mathrm{kg}^{-1}$ de N. Esses autores não encontraram diferenças nos teores de $\mathrm{N}_{\text {mic }}$ entre o plantio direto e o preparo reduzido com escarificador.

Quadro 6. Comparação dos estimadores do parâmetro $p_{0}$ da regressão $\hat{y}=p_{0}+p_{1} x_{L}$ para nitrogênio da biomassa microbiana $\left(\mathrm{N}_{\text {mic }}\right)$ em oito tratamentos e em três épocas de amostragem

\begin{tabular}{|c|c|c|c|}
\hline \multirow{2}{*}{ Tratamento } & \multicolumn{3}{|c|}{ Intercepto $p_{0}$ para as épocas } \\
\hline & Antes do plantio (*) & 30 DAE $(*)$ & Floração (ns) \\
\hline $\operatorname{ADPP}^{(1)}$ & $16,5 \mathrm{bc}^{(2)}$ & $26,2 \mathrm{a}$ & $20,1 \mathrm{a}$ \\
\hline $\mathrm{ADPC}$ & $14,0 \mathrm{c}$ & $13,3 \mathrm{c}$ & $14,4 \mathrm{a}$ \\
\hline ESCAD & $18,9 \mathrm{bc}$ & $20,4 \mathrm{abc}$ & 19,5 a \\
\hline PDAD & 28,1 a & $22,7 \mathrm{ab}$ & $23,1 \mathrm{a}$ \\
\hline AVPP & $17,8 \mathrm{bc}$ & $16,8 \mathrm{bc}$ & $14,4 \mathrm{a}$ \\
\hline AVPC & $11,7 \mathrm{c}$ & $15,7 \mathrm{bc}$ & $14,4 \mathrm{a}$ \\
\hline ESCAV & $20,4 \mathrm{abc}$ & $20,9 \mathrm{abc}$ & $17,7 \mathrm{a}$ \\
\hline PDAV & $22,9 \mathrm{ab}$ & $17,8 \mathrm{bc}$ & $16,7 \mathrm{a}$ \\
\hline
\end{tabular}

(1) Idem à descrição apresentada no quadro 4. ${ }^{(2)}$ Valores seguidos da mesma letra na coluna não apresentam diferenças significativas entre si pelo teste t a $5 \%$.

*: Significativo a $5 \%$; ns: não-significativo pelo teste $\mathrm{F}$. 
Todos os tratamentos apresentaram os estimadores do parâmetro de tendência linear $\left(\mathrm{p}_{1}\right)$ negativos, na época antes do plantio (Quadro 7). Na floração, o tratamento PDAV apresentou $\mathrm{N}_{\text {mic }}\left(\mathrm{p}_{1}=\right.$ -2,89 $\mathrm{mg} \mathrm{kg}^{-1}$ de $\mathrm{N}$ de solo por $\mathrm{cm}$ de profundidade) superior ao dos tratamentos ADPC, ESCAV e AVPC ( $p_{1}=-0,30 ;-0,84$ e $0,12 \mathrm{mg} \mathrm{kg}^{-1}$, respectivamente). O tratamento com arado de aivecas AVPC causou pequeno acréscimo de $\mathrm{N}_{\text {mic }}$ com a profundidade (Quadro 7).

Pelo modelo de regressão linear não-ortogonal, antes do plantio, observou-se que os sistemas sem revolvimento ou com revolvimento mínimo apresentaram decréscimos mais acentuados nos teores de $\mathrm{N}_{\text {mic }}$ em profundidade, considerando o perfil de 0 a $40 \mathrm{~cm}$ (Figura 1). Por sua vez, os sistemas ADPP e AVPP mostraram menores decréscimos no teor de $\mathrm{N}_{\text {mic }}$ no solo com a profundidade $(\mathrm{ESCAV}>\mathrm{PDAD}=\mathrm{PDAV}>$ ESCAD > ADPP > AVPP), o que pode ser efeito do revolvimento do solo e da ação homogeneizadora da aração. As equações para ADPC e AVPC não foram significativas. Quanto mais conservacionista o sistema, maior o acúmulo de $\mathrm{N}$ na superfície, imobilizado na biomassa microbiana.

Em plantio direto, Carter \& Rennie (1984) observaram imobilização de $\mathrm{N}$ fertilizante adicionado, principalmente, na camada de 0 a $5 \mathrm{~cm}$, sendo esta menor na profundidade de 5 a $10 \mathrm{~cm}$.

\section{Relação carbono:nitrogênio da biomassa microbiana}

Considerando o efeito médio do perfil, observa-se no quadro 8 que, na época antes do plantio, o tratamento AVPC $\left(\mathrm{p}_{0}=26,4\right)$ mostrou relação $\mathrm{C}_{\text {mic }}: \mathrm{N}_{\text {mic }}$ superior à de todos os sistemas em que se utilizaram em algum momento o arado de discos e o

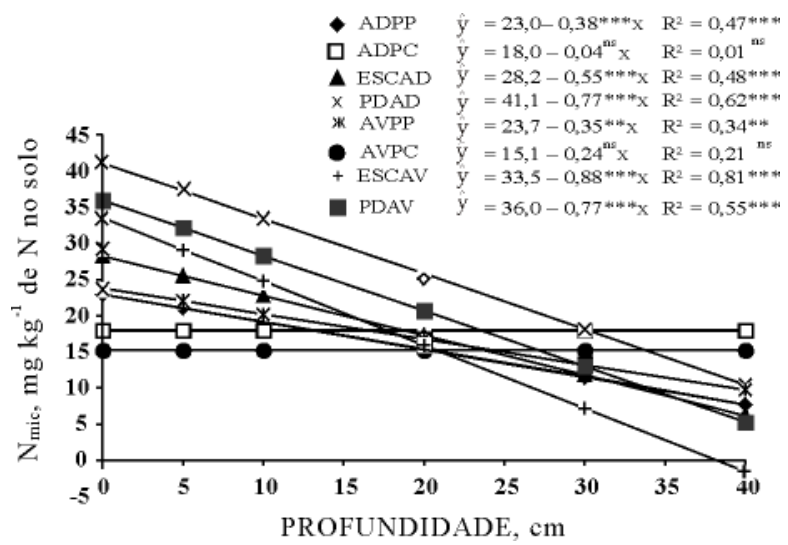

Figura 1. Regressão linear de $\mathrm{N}_{\text {mic }}$ de acordo com a profundidade do solo para os oito sistemas de manejo, na amostragem antes do plantio.

$\operatorname{AVPP}\left(\mathrm{p}_{0}=9,64\right)$, não diferindo daqueles em que se empregou em algum momento o arado de aivecas (ESCAV e PDAV; 13,5 e 14,4, respectivamente). Isso indica que o modo de ação deste implemento possibilita a atuação de grupos diferenciados de microrganismos. A relação $\mathrm{C}_{\text {mic }}: \mathrm{N}_{\text {mic }}$ é freqüentemente usada para descrever a estrutura e o estado da comunidade microbiana (Moore et al., 2000). Alta relação $\mathrm{C}_{\text {mic }}: \mathrm{N}_{\text {mic }}$ indica que a comunidade microbiana contém maior proporção de fungos, enquanto baixo valor sugere que bactérias predominam na população microbiana (Campbell et al., 1991).

Essa relação é afetada pelas propriedades do solo, tais como: teor de água, textura, $\mathrm{pH}$, relações $\mathrm{C}_{\text {mic }}$ : $\mathrm{C}_{\text {org }}$ e $\mathrm{N}_{\text {mic }}: \mathrm{N}_{\text {total }}$, incorporação de $\mathrm{N}$ em fungos e relação entre microrganismos ativos e dormentes (Anderson \& Domsch, 1980; Campbell et al., 1991). Em sistemas com preparo convencional do solo, a incorporação de

Quadro 7. Comparação dos estimadores do parâmetro $p_{1}\left(\mathrm{mg} \mathrm{kg}^{-1} \mathrm{~cm}^{-1}\right)$ da regressão $\hat{y}=p_{0}+p_{1} x_{L}$ para nitrogênio da biomassa microbiana $\left(\mathrm{N}_{\text {mic }}\right)$ em oito tratamentos e em três épocas de amostragem

Tratamento

Parâmetro p para as épocas

Antes do plantio (ns) 30 DAE (ns) Floração (*)

$-\mathrm{mg} \mathrm{kg}^{-1}$ de $\mathrm{N}$ por $\mathrm{cm}$ de profundidade

$\begin{array}{llcl}\text { ADPP(1) } & -0,95 \mathrm{a} & 0,48 \mathrm{a} & -1,35 \mathrm{abc}^{(2)} \\ \text { ADPC } & -1,16 \mathrm{a} & -0,40 \mathrm{a} & -0,30 \mathrm{a} \\ \text { ESCAD } & -1,37 \mathrm{a} & -1,49 \mathrm{a} & -1,62 \mathrm{abc} \\ \text { PDAD } & -1,92 \mathrm{a} & -2,23 \mathrm{a} & -2,41 \mathrm{ac} \\ \text { AVPP } & -0,88 \mathrm{a} & -0,58 \mathrm{a} & -1,24 \mathrm{abc} \\ \text { AVPC } & -0,38 \mathrm{a} & 0,02 \mathrm{a} & 0,12 \mathrm{a} \\ \text { ESCAV } & -2,38 \mathrm{a} & -1,70 \mathrm{a} & -0,84 \mathrm{ab} \\ \text { PDAV } & -1,93 \mathrm{a} & -1,34 \mathrm{a} & -2,89 \mathrm{c}\end{array}$

${ }^{(1)}$ Idem à descrição apresentada no quadro $4 .{ }^{(2)}$ Valores seguidos da mesma letra na coluna não apresentam diferenças significativas entre si pelo teste $\mathrm{t}$ a $5 \%$.

*: Significativo a $5 \%$; ns: não-significativo pelo teste F. 
Quadro 8. Comparação dos estimadores dos parâmetros $p_{0} e p_{1}$ da regressão $\hat{y}=p_{0}+p_{1} x_{L}$ para relação carbono:nitrogênio da biomassa microbiana $\left(\mathrm{C}_{\text {mic }}: \mathrm{N}_{\text {mic }}\right)$ em oito tratamentos e em três épocas de amostragem

\begin{tabular}{llc}
\hline & \multicolumn{2}{c}{ Parâmetro } \\
\cline { 2 - 3 } Tratamento & $\mathbf{P}_{\mathbf{0}}\left(^{*}\right)$ & $\mathbf{P}_{\mathbf{1}}\left({ }^{*}\right)$ \\
\hline ADPP(1) & $172 \mathrm{bc}^{(2)}$ & $-8,60 \mathrm{abc}$ \\
ADPC & $140 \mathrm{c}$ & $-10,1 \mathrm{bc}$ \\
ESCAD & $237 \mathrm{a}$ & $-14,9 \mathrm{c}$ \\
PDAD & $156 \mathrm{c}$ & $-18,7 \mathrm{c}$ \\
AVPP & $144 \mathrm{c}$ & $-2,94 \mathrm{ab}$ \\
AVPC & $190 \mathrm{abc}$ & $2,25 \mathrm{a}$ \\
ESCAV & $182 \mathrm{abc}$ & $-13,2 \mathrm{bc}$ \\
PDAV & $227 \mathrm{ab}$ & $-15,8 \mathrm{c}$
\end{tabular}

(1) Idem à descrição apresentada no quadro 4. ${ }^{(2)}$ Valores seguidos da mesma letra na coluna não apresentam diferenças significativas entre si pelo teste t a $5 \%$.

*: Significativo a $5 \%$ pelo teste F.

resíduos favorece a dominância de bactérias, ao passo que no plantio direto filamentos fúngicos são relativamente mais abundantes. Essa mudança na estrutura das comunidades microbianas tem implicações importantes para o estoque da MOS (Guggenberger et al., 1999).

Outro ponto interessante a ressaltar é que, mesmo tendo havido apenas um ano de utilização do arado de aivecas nos tratamentos sob plantio direto e com o escarificador, o seu efeito de incorporação profunda permaneceu ao longo de todos esses anos.

$\mathrm{Na}$ figura 2, observa-se que o sistema ESCAV apresentou acentuado acréscimo na relação $\mathrm{C}_{\text {mic }}: \mathrm{N}_{\text {mic }}$ em profundidade, considerando o perfil de 0 a $40 \mathrm{~cm}$ do solo, enquanto os sistemas ADPC e PDAD, dois modelos não-ortogonais significativos, apresentaram pequeno decréscimo nessa relação com a profundidade. Esses resultados reforçam a indicação de que grupos diferenciados de microrganismos estão relacionados aos efeitos dos diferentes implementos.

\section{Carbono da biomassa microbiana, considerando todas as épocas de amostragem}

Considerando-se todas as épocas de amostragem, em média, o sistema ESCAD apresentou valor de $\mathrm{C}_{\text {mic }}$ ( $\mathrm{p}_{0}=237 \mathrm{mg} \mathrm{kg}^{-1} \mathrm{de}$ C no solo) (Quadro 9) superior ao dos sistemas ADPP, ADPC, PDAD e AVPP (172, 140, 156 e $144 \mathrm{mg} \mathrm{kg}^{-1}$ de $\mathrm{C}$, respectivamente). Além do elevado teor de $\mathrm{C}_{\text {mic }}$ no tratamento com escarificador (ESCAD), observa-se que houve diferença significativa entre os dois sistemas sob plantio direto: o PDAV $\left(\mathrm{p}_{0}=227 \mathrm{mg} \mathrm{kg}^{-1} \mathrm{de} \mathrm{C}\right)$ apresentou $\mathrm{C}_{\text {mic }} 1,46$ vez maior que o PDAD.

Quanto ao parâmetro $\mathrm{p}_{1}$ estimado, com exceção do sistema AVPC (Quadro 9), todos os outros apresentaram

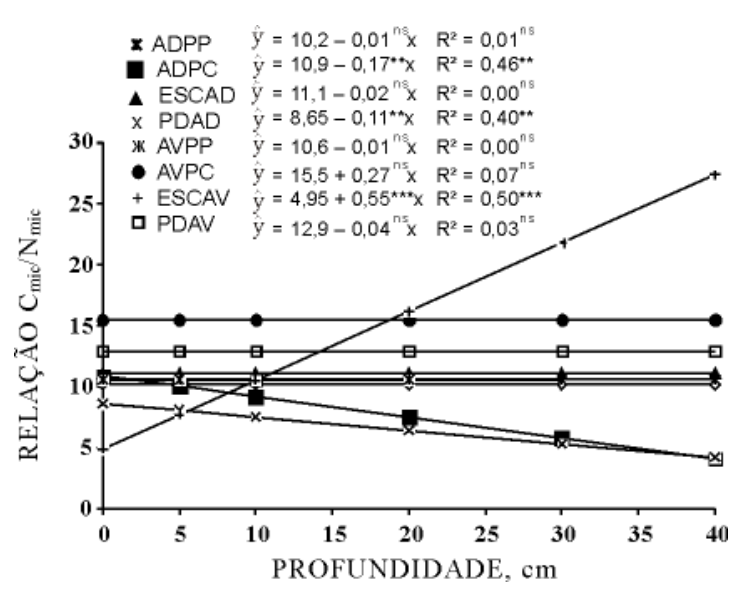

Figura 2. Regressão linear de $C_{\text {mic }}: N_{\text {mic }}$ de acordo com a profundidade do solo para os oito sistemas de manejo, na amostragem antes do plantio.

valores negativos, indicando decréscimo da biomassa microbiana com a profundidade. OAVPC $\left(\mathrm{p}_{1}=\right.$ $2,25 \mathrm{mg} \mathrm{kg}^{-1}$ de $\mathrm{C}$ de solo por $\mathrm{cm}$ de profundidade) só não diferiu dos sistemas $\operatorname{ADPP}$ e $\operatorname{AVPP}\left(\mathrm{p}_{1}=-8,60 \mathrm{e}\right.$ $2,94 \mathrm{mg} \mathrm{kg}^{-1} \mathrm{~cm}^{-1}$ de $\mathrm{C}$, respectivamente).

Com exceção dos tratamentos em que se utilizou o arado de aivecas (AVPC e AVPP), todos os outros apresentaram acentuado decréscimo do $\mathrm{C}_{\text {mic }}$ com a profundidade, especialmente aqueles sob plantio direto (PDAD e PDAV).

\section{Nitrogênio da biomassa microbiana, consideran- do todas as épocas de amostragem}

$\mathrm{O}$ sistema PDAD apresentou valor de $\mathrm{N}_{\text {mic }}$ ( $\mathrm{p}_{0}=24,8 \mathrm{mg} \mathrm{kg}^{-1}$ de $\mathrm{N}$ no solo) (Quadro 10) significativamente maior que o de todos os outros, com 
Quadro 9. Comparação dos estimadores dos parâmetros $\mathbf{p}_{0}$ e $\mathbf{p}_{1}$ da regressão $\hat{\mathbf{y}}=\mathbf{p}_{0}+\mathbf{p}_{1} \mathbf{x}_{\mathrm{L}}$, para carbono da biomassa microbiana em oito tratamentos, considerando todas as épocas de amostragem, em média

\begin{tabular}{llc}
\hline & & Parâmetro \\
\cline { 2 - 3 } Tratamento & $\left.\mathbf{P}_{\mathbf{0}} \mathbf{c}^{*}\right)$ & $\mathbf{P}_{\mathbf{1}}(*)$ \\
\hline & $\mathrm{mg} \mathrm{kg}^{-1}$ & $\mathrm{mg} \mathrm{kg}^{-1} \mathrm{~cm}^{-1}$ \\
ADPP(1) & $172 \mathrm{bc}^{(2)}$ & $-8,60 \mathrm{abc}$ \\
ADPC & $140 \mathrm{c}$ & $-10,1 \mathrm{bc}$ \\
ESCAD & $237 \mathrm{a}$ & $-14,9 \mathrm{c}$ \\
PDAD & $156 \mathrm{c}$ & $-18,7 \mathrm{c}$ \\
AVPP & $144 \mathrm{c}$ & $-2,94 \mathrm{ab}$ \\
AVPC & $190 \mathrm{abc}$ & $2,25 \mathrm{a}$ \\
ESCAV & $182 \mathrm{abc}$ & $-13,2 \mathrm{bc}$ \\
PDAV & $227 \mathrm{ab}$ & $-15,8 \mathrm{c}$ \\
\hline
\end{tabular}

${ }^{(1)}$ Idem à descrição apresentada no quadro $4 .{ }^{(2)}$ Valores seguidos da mesma letra na coluna não apresentam diferenças significativas entre si pelo teste t a $5 \%$. *: Significativo a $5 \%$ pelo teste $\mathrm{F}$.

Quadro 10. Comparação dos estimadores dos parâmetros $p_{0} e p_{1}$ da regressão $\hat{y}=p_{0}+p_{1} x_{L}$ para nitrogênio da biomassa microbiana em oito tratamentos, considerando todas as épocas de amostragem, em média

\begin{tabular}{lll}
\hline & & Parâmetro \\
\cline { 2 - 3 } Tratamento & $\mathbf{P}_{\mathbf{0}}(* *)$ & $\mathbf{P}_{1}(* *)$ \\
\hline & $\mathrm{mg} \mathrm{kg}^{-1}$ & $\mathrm{mg} \mathrm{kg}^{-1} \mathrm{~cm}^{-1}$ \\
ADPP(1) & $20,9 \mathrm{ab}^{(2)}$ & $-0,61 \mathrm{ab}$ \\
ADPC & $13,9 \mathrm{~d}$ & $-0,62 \mathrm{ab}$ \\
ESCAD & $19,6 \mathrm{bc}$ & $-1,49 \mathrm{bcd}$ \\
PDAD & $24,8 \mathrm{a}$ & $-2,16 \mathrm{~d}$ \\
AVPP & $16,3 \mathrm{~cd}$ & $-0,90 \mathrm{abc}$ \\
AVPC & $14,0 \mathrm{~d}$ & $-0,08 \mathrm{a}$ \\
ESCAV & $19,6 \mathrm{bc}$ & $-1,74 \mathrm{~cd}$ \\
PDAV & $19,1 \mathrm{bc}$ & $-2,05 \mathrm{~d}$ \\
\hline
\end{tabular}

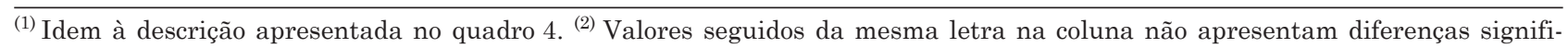
cativas entre si pelo teste t a $5 \%$.**: Significativo a $1 \%$ pelo teste $\mathrm{F}$.

exceção do $\operatorname{ADPP}\left(\mathrm{p}_{0}=20,9 \mathrm{mg} \mathrm{kg}^{-1} \mathrm{de} \mathrm{N}\right)$. Este último apresentou valor de $\mathrm{N}_{\text {mic }} 1,5 \mathrm{vez}$ maior do que o sistema com arado de discos com duplo revolvimento anual do solo para incorporação dos resíduos da cultura pós-colheita e para plantio da próxima cultura (ADPC, $\left.\mathrm{p}_{0}=13,9 \mathrm{mg} \mathrm{kg}^{-1} \mathrm{de} \mathrm{N}\right)$, indicando que há diminuição da biomassa com o aumento da freqüência de revolvimento, embora isso dependa do tipo de implemento, pois nos tratamentos AVPP e AVPC, que não diferiram do $\mathrm{ADPC}$, não se observou esse efeito.

Considerando o estimador do parâmetro $\mathrm{p}_{1}$, com tendência linear para $\mathrm{N}_{\text {mic }}($ Quadro 10), verifica-se que os sistemas com nenhum ou pouco revolvimento do solo - PDAD, PDAV, ESCAD e ESCAV (-2,16, -2,05, $-1,49$ e $-1,74 \mathrm{mg} \mathrm{kg}^{-1}$ de $\mathrm{N}$ no solo por $\mathrm{cm}$ de profundidade, respectivamente) -, não diferiram entre si. Entretanto, os sistemas PDAD e PDAV mostraram valores de $\mathrm{p}_{1}$ superiores aos dos sistemas ADPP, ADPC, AVPP e AVPC $(3,5 ; 3,4 ; 2,3$ e 26,3 vezes, respectivamente).

As influências dos sistemas de cultivo mínimo e sob plantio direto em relação ao $\mathrm{C}_{\text {mic }}$ e ao $\mathrm{N}_{\text {mic }}$ foram 
inversas (Quadros 9 e 10). No que se refere aos valores de $\mathrm{p}_{0}$ para $\mathrm{C}_{\text {mic }}$, a ordem foi: $\mathrm{ESCAD}>\mathrm{PDAD}$ e ESCAD $=\mathrm{PDAV}=\mathrm{ESCAV}$, e para os valores de $\mathrm{p}_{0}$ para $\mathrm{N}_{\text {mic }}$ a ordem foi: $\mathrm{PDAD}>\mathrm{ESCAD}$ e $\mathrm{PDAD}>\mathrm{ESCAV}=$ PDAV. Considerando-se o teor de $\mathrm{C}_{\text {mic }}$ (Quadro 9), o plantio direto PDAV apresentou-se superior ao PDAD, tendo sido 1,5 vez maior; já em relação ao $\mathrm{N}_{\text {mic }}$, essa situação se inverteu: o valor de $\mathrm{N}_{\text {mic }}$ no PDAD $\left(\mathrm{p}_{0}=24,8 \mathrm{mg} \mathrm{kg}^{-1}\right)$ foi 1,3 vez maior do que no PDAV $\left(\mathrm{p}_{0}=19,1 \mathrm{mg} \mathrm{kg}^{-1}\right)$ (Quadro 10). Resck \& Silva (1995) encontraram diferenças entre esses dois sistemas para alguns atributos do solo nesse mesmo experimento, em especial o teor de MOS, que foi maior no PDAV do que no PDAD. Entretanto, a meia-vida da MOS no PDAD foi quase duas vezes maior do que no PDAV. Esses resultados, somados aos valores de $\mathrm{C}_{\text {mic }}$ e $\mathrm{N}_{\text {mic }}$ encontrados nesses sistemas, reforçam a constatação feita por Resck (1998), de que, para os solos do Cerrado, pobres quimicamente, é necessário implantar uma dinâmica de sistemas de preparo do solo antes do estabelecimento do sistema plantio direto.

Relação C:N da biomassa microbiana, considerando todas as épocas de amostragem, em média

Os valores de $\mathrm{C}_{\text {mic }}: \mathrm{N}_{\text {mic }}$ variaram de 6,07 (ADPP) a 15,5 (AVPC) (Quadro 11), situando-se dentro da faixa registrada na literatura. Em estudos com 38 solos da Alemanha, Joergensen et al. (1995) encontraram variação nessa relação entre 5,4 e 17,3.

$\mathrm{O}$ sistema AVPC $\left(\mathrm{p}_{0}=15,5\right)$ apresentou relação $\mathrm{C}_{\text {mic }}: \mathrm{N}_{\text {mic }}$ maior do que as dos sistemas em que se utilizou em algum momento o arado de discos, com exceção do $\operatorname{ESCAD~}\left(\mathrm{p}_{0}=12,93\right)$. Esses resultados

Quadro 11. Comparação dos estimadores do intercepto $p_{0}$ da regressão $\hat{y}=p_{0}+p_{1} x_{L}$ para a relação carbono:nitrogênio da biomassa microbiana em oito tratamentos, considerando todas as épocas de amostragem, em média

Tratamento

$p_{0}(*)$

\begin{tabular}{lc} 
& \\
\hline & $\mathrm{C}_{\text {mic }}: \mathrm{N}_{\text {mic }}$ \\
ADPP(1) & $6,07 \mathrm{c}^{(2)}$ \\
ADPC & $8,83 \mathrm{bc}$ \\
ESCAD & $12,9 \mathrm{ab}$ \\
PDAD & $6,59 \mathrm{bc}$ \\
AVPP & $7,85 \mathrm{bc}$ \\
AVPC & $15,5 \mathrm{a}$ \\
ESCAV & $11,8 \mathrm{abc}$ \\
PDAV & $13,1 \mathrm{ab}$
\end{tabular}

(1) Idem à descrição apresentada no quadro 4. ${ }^{(2)}$ Valores seguidos da mesma letra na coluna não apresentam diferenças significativas entre si pelo teste t a $5 \%$.

*: Significativo a $5 \%$ pelo teste F. indicam que, nos sistemas que incluem o arado de aivecas, o teor de $\mathrm{C}_{\text {mic }}$ é maior do que o de $\mathrm{N}_{\text {mic }}$ na profundidade de 0 a $40 \mathrm{~cm}$ do solo. Também deve ser destacada a exceção encontrada para o sistema AVPP, com valor menor de $\mathrm{C}_{\text {mic }}$ e maior de $\mathrm{N}_{\text {mic }}$ do que o AVPC, embora não-significativos, com efeito linear decrescente em relação à profundidade do solo (Quadros 9 e 10, respectivamente). O número diferenciado de revolvimento do solo durante o ano, por um longo período, pode ter sido a explicação para que isso ocorresse. $\mathrm{O}$ estimador do parâmetro $\mathrm{p}_{1}$ não foi significativo pelo teste $\mathrm{F}$.

\section{CONCLUSÕES}

1. Os sistemas de manejo influenciaram diferentemente os teores de $\mathrm{C}_{\text {mic }}$ e $\mathrm{N}_{\text {mic }}$ : nos tratamentos sob plantio direto, o PDAV superou o PDAD nos teores de $\mathrm{C}_{\text {mic }}$, mas o oposto ocorreu para o conteúdo de $\mathrm{N}_{\text {mic }}$, indicando que os ambientes proporcionados pelos arados de discos e aivecas no perfil persistiram mesmo após 22 anos sob plantio direto.

2. Em geral, quanto mais conservacionista o sistema, maior o acúmulo de $\mathrm{N}$ na superfície, imobilizado na biomassa microbiana.

3. A época de incorporação dos restos culturais (revolvimento único ou duplo do solo) influenciou a dinâmica dos reservatórios de $\mathrm{N}$ de solo, no sistema sob arado de discos. O ADPP apresentou maiores teores de $\mathrm{N}_{\text {mic }}$, considerando todas as amostragens, em média.

4. De maneira geral, as maiores diferenças entre os sistemas de manejo foram verificadas antes do plantio, portanto, ocorreram antes do revolvimento e, ou, da adubação e do estabelecimento da cultura.

\section{LITERATURA CITADA}

ADÁMOLI, J.; MACEDO, J.; AZEVEDO, L.G. \& MADEIRA NETO, J. Caracterização da região dos Cerrados. In: GOEDERT, W.J. Solos dos Cerrados: Tecnologias e estratégias de manejo. Planaltina/São Paulo, EmbrapaCPAC/Nobel, 1986. p.33-74.

ALVAREZ, C.R.; ALVAREZ, R.; GRIGERA, M.S. \& LAVADO, R.S. Associations between organic matter fractions and the active soil microbial biomass. Soil Biol. Biochem., 30:767-773, 1997.

ALVAREZ, R.; DÍAZ, R.A.; BARBERO, N.; SANTA-NATOGLIA, O.J. \& BLOTTA, L. Soil organic carbon, microbial biomass and $\mathrm{CO}_{2}-\mathrm{C}$ production from three tillage systems. Soil Till. Res., 33:17-28, 1995.

ANDERSON, J.P.E. \& DOMSCH, K.H. Quantities of plant nutrients in the microbial biomass of selected soils. Soil Sci., 130:211-216, 1980.

BALOTA, E.L.; COLOZZI-FILHO, A.; ANDRADE, D.S. \& HUNGRIA, M.R. Biomassa microbiana e sua atividade em solos sob diferentes sistemas de preparo e sucessão de culturas. R. Bras. Ci. Solo, 22:641-649, 1998. 
BONDE, T.A.; SCHNÜRER, J. \& ROSSWALL, T. Microbial biomass as a fraction of potentially mineralizable nitrogen in soils from long-term field experiments. Soil Biol. Biochem., 20:447-452, 1988.

BROOKES, P.C.; LANDMAN, A.; PRUDEN, G. \& JENKINSON, D.S. Chloroform fumigation and the release of soil nitrogen: A rapid direct extraction method to measure microbial biomass nitrogen in soil. Soil Biol. Biochem., 17:837-842, 1985.

CAMPBELL, C.A.; BIEDERBECK, V.O.; ZENTNER, R.P. \& LAFOND, G.P. Effect of crop rotations and cultural practices on soil organic matter, microbial biomass and respiration in a thin black Chernozem. Can. J. Soil Sci., 71:363-376, 1991.

CARTER, M.R. \& RENNIE, D.A. Changes in soil quality under zero tillage farming systems: Distribution of microbial biomass and mineralizable $\mathrm{C}$ and $\mathrm{N}$ potentials. Can. J. Soil Sci., 62:587-597, 1982.

CARTER, M.R. \& RENNIE, D.A. Crop utilization of placed and broadcasted ${ }^{15} \mathrm{~N}$ urea fertilizer under zero and conventional tillage. Can. J. Soil Sci., 64:563-570, 1984.

CORAZZA, E.J.; SILVA, J.E.; RESCK, D.V.S. \& GOMES, A.C. Comportamento de diferentes sistemas de manejo como fonte ou depósito de carbono em relação à vegetação de Cerrado. R. Bras. Ci. Solo, 23:425-432, 1999.

COLWELL, J.D. Computations for studies of soil fertility and fertilizer requirements. Camberra, CSFRO Division of Soils, A.C.T. Australia Commonwealth Agricultural Bureau, 1978. 297p.

DE-POLLI, H. \& GUERRA, J.G.M. C, N e P na biomassa microbiana do solo. In: SANTOS, G.A. \& CAMARGO, F.A.O. Fundamentos da matéria orgânica do solo: Ecossistemas tropicais e subtropicais. Porto Alegre, Gênesis, 1999. p.389-411.

EMPRESA BRASILEIRA DE PESQUISA AGROPECUÁRIA EMBRAPA. Centro Nacional de Pesquisa de Solos. Manual de métodos de análise de solo. 2.ed. Rio de Janeiro, 1997. $212 p$.

FRANCIS, G.S.; HAYNES, R.J. \& KNIGHT, T.L. An overview of results from the long-term no-tillage trials at Winchmore. In: ANNUAL CONFERENCE OF THE AGRONOMY SOCIETY OF NEW ZEALAND, 1992. Camberra. Proceedings. Camberra, 1992. v.22. p.97-101.

GUGGENBERGER, G.; FREY, S.D.; SIX, J.; PAUSTAN, K. \& ELLIOTT, E.T. Bacterial and fungal cell-wall residues in conventional and no-tillage agroecosystems. Soil Sci. Soc. Am. J., 63:1188-1198, 1999.

JENKINSON, D.S. \& POWLSON, D.S. The effects of biocidal treatments on metabolism in soil: A method for measuring soil biomass. Soil Biol. Biochem., 8:209-213, 1976.

JOERGENSEN, R.G.; ANDERSON, T.H. \& WOLTERS, V. Carbon and nitrogen relationships in the microbial biomass of soil in beech (Fagus sylvatica L.) forests. Soil Biol. Biochem., 27:141-147, 1995.

JOERGENSEN, R.G. The fumigation-extraction method to estimate soil microbial biomass: Calibration of the $\mathrm{k}_{\mathrm{ec}}$ value. Soil Biol. Biochem., 28:25-31, 1995.
LYNCH, J.M. \& PANTING, L.M. Cultivation and the soil biomass. Soil Biol. Biochem., 12:29-33, 1980.

MACIEL, M.M.F.; MELO, W.J.; CHELLE, R.A. \& LEITE, S.A.S. Nitrogênio da biomassa microbiana de solos hidromórficos e Latossolos do Cerrado de Planaltina (DF). In: REUNIÃO BRASILEIRA DE FERTILIDADE DO SOLO E NUTRIÇÃO DE PLANTAS, 22., Fortaleza, 1996. Resumos. Fortaleza, 1996. p.556-557.

MOORE, J.M.; KLOSE, S. \& TABATABAI, M.A. Soil microbial biomass carbon and nitrogen as affected by cropping systems. Biol. Fert. Soils, 31:200-210, 2000.

OLIVEIRA, J.R.A. O impacto de sistemas integrados de lavouras e pastagens na biomassa-C e na atividade biológica de um Latossolo Vermelho-Escuro de Cerrado. Brasília, Universidade de Brasília, 2000. 115p. (Tese de Mestrado)

RESCK, D.V.S. Agricultural intensification systems and their impact on soil and water quality in the Cerrados of Brazil. In: LAL, R. Soil quality and agricultural sustainability. Chelsea, Ann Arbor Press, 1998. p.288-300.

RESCK, D.V.S.; FERREIRA, C.A.; GOMES, A.C. \& SILVA, J.E. Efeito do plantio direto e do arado de discos nas propriedades físicas de um Latossolo Vermelho-Escuro argiloso sob vegetação de Cerrados. In: CONGRESSO BRASILEIRO DE CIÊNCIA DO SOLO, 25., Viçosa, MG 1995. Anais. Viçosa, MG , Sociedade Brasileira de Ciência do Solo, 1995. v.4. p.1840-1842.

RESCK, D.V.S. O plantio direto como alternativa de sistema de manejo e conservação do solo e da água na região dos Cerrados. In: CONGRESSO BRASILEIRO DE CIÊNCIA DO SOLO, 26., Rio de Janeiro, 1997. Anais. Rio de Janeiro, Embrapa/CBCS, 1997. CD-ROM

RESCK, D.V.S. \& SILVA, J.E. Efeito de diferentes sistemas de preparo do solo no teor e na meia-vida da matéria orgânica de um Latossolo Vermelho-Escuro argiloso na região dos Cerrados. In: CONCRESSO BRASILEIRO DE CIÊNCIA DO SOLO, 25., Viçosa, MG, 1995. Resumos. Viçosa, Sociedade Brasileira de Ciência do Solo, 1995. p.1837-1839.

SALINAS-GARCIA, J.R.; HONS, F.M. \& MATOCHA, J.E. Long-term effects of tillage and fertilization on soil organic matter dynamics. Soil Sci. Soc. Am. J., 1:152-159, 1997.

SAMINÊZ, T.C.O. Efeito do sistema de cultivo, tensão da água, biomassa microbiana e temperatura do solo nos fluxos de $\mathrm{CH}_{4}$ e $\mathrm{N}_{2} \mathrm{O}$ em solos de Cerrados. Brasília, Universidade de Brasília, 1999. 99p. (Tese de Mestrado)

SILVA, J.E. \& RESCK, D.V.S. Matéria orgânica do solo. In: VARGAS, M.A.T. \& HUNGRIA, M. Biologia dos solos dos Cerrados. Planaltina, Embrapa, 1997. p.467-524.

VANCE, E.D.; BROOKES, P.C. \& JENKINSON, D.S. An extraction method for measuring soil microbial biomass C. Soil Biol. Biochem., 19:703-707, 1987.

VARGAS, L.K. \& SCHOLLES, D. Nitrogênio da biomassa microbiana em solos sob diferentes sistemas de manejo, estimado por métodos de fumigação. R. Bras. Ci. Solo, 22:411-417, 1998

WARDLE, D.A. A comparative assessment of factors which influence microbial biomass carbon and nitrogen levels in soil. Biol. Rev., 67:321-358, 1992. 